\title{
Auditing of Nursing care for Patient with Upper Gastrointestinal Tract Bleeding at El -Rajhi Hospital
}

\author{
Madiha Mahammad Hassan, Zienab Abd-El-Latif Mohammad, Saad Zaki Mahmoud \& Hanan Abd Elrazik \\ Abd Elall. \\ Head Nurse of Tropical Medicine and Gastroenterology at El -Rajhi hospital, Assiut University, Egypt. \\ Professor of Medical, Surgical Nursing, faulty of Nursing, Assiut University, Egypt. \\ Professor of Tropical Medicine and Gastroenterology, faculty of Medicine, Assiut University, Egypt. \\ Lecturer of Medical Surgical Nursing faulty of Nursing- Assiut University, Egypt.
}

\begin{abstract}
Audit it is a systemic review and evaluation of records and other data to determine the quality of the services provided in a given situation. Upper gastrointestinal tract bleeding is the most common emergency and can potentially lead to serious hemodynamic compromise and mortality. Aims of the study: General aim; auditing of nursing care for patient with upper gastrointestinal tract bleeding. Specific aims; To assess current nursing management for patient with upper GIT bleeding .To develop nursing care standers for patient with upper GIT bleeding. And to identify the gap between the current nursing management and nursing care standers for patient with upper GIT bleeding .Subjects and methods: a descriptive research design. Sample: (60) nurses working at the Tropical, 'Gastroenterology and Internal medicine department at El-Rajhi hospital, Assuit University . Tool utilized for data collection are assessment of current nursing management for patient with upper gastrointestinal bleeding. Results: the majority of nursing has satisfactory level of knowledge (73\%) but above third of nurse's perform the steps of observation checklist correctly Conclusion: Positive correlation between nursing standard and total practice $\&$ knowledge score. In addition of a gap between routine nursing care and nursing standard Recommendation Witten standard of nursing care for nurse to monitoring the routine nursing care daily.
\end{abstract}

\section{Key words : Auditing, Nursing Care \& Upper Gastrointestinal Tract Bleeding.}

\section{Introduction}

Health audit has demonstrated that it is possible to provide patients with quality care at a fair and affordable cost. The audit is defined as a set of measures by which an internal or external auditor analyzes the operational activities, aiming to evaluate the quality of services offered (Johnston et al., 2010).

Upper gastrointestinal bleeding is a potentially life threatening condition that requires a prompt and appropriate nursing management, representing a significant clinical and economic burden. Acute upper gastrointestinal hemorrhage is a common condition worldwide that has an estimated annual incidence of (40-150) cases per 100000 populations, frequently leads to hospital admission and has significant associated morbidity and mortality especially in adult patient (Horve et al., 2019).

The most common causes of upper GIT bleeding are non-variceal This includes peptic, duodenal, gastric ulcer, mucosal erosive disease of the esophagus, stomach and duodenum, malignancy (Gralnek et al., 2015).

A cute upper gastro-intestinal bleeding may originate in the esophagus, stomach, and duodenum .It can be categorized based upon anatomic and pathophysiologic factors as: ulcerative and other nonsteroidal anti- inflammatory drugs, traumatic, tumors and portal hypertension, Mallory-Weiss tear and neoplasms including gastric cancers. Other relatively common causes include esophagitis, erosive gastritis duodenitis (Diab et al., 2018).

The purpose of a standard of nursing care for patient with upper gastrointestinal bleeding is to establish the best practice and eliminate as much variation as possible. Standard of care often include aspects of medical care various therapies as well as nursing care. They identify specific desired outcomes for each day of hospitalization and actions that are to be taken to achieve those outcomes (Wong et al., 2015).

\section{Significance of the study}

From the researcher clinical experience it has been observed that; patient with upper gastrointestinal bleeding need detailed evaluation of many component of health care throughout relevant audit car standards. Therefore, this study was the first in this geographical location which could be helpful for health professional especially nursing in planning and implementation care for such group of patient.

\section{Aim of the study}

1. To assess current nursing performance for patients with upper gastrointestinal tract bleeding.

2. To develop nursing care standards for patients with upper gastrointestinal tract bleeding. 
3. To identify the gap between the current nursing management and nursing care standard for patients with upper gastrointestinal tract bleeding.

\section{Research Questions}

Is there is a gap between the current nursing management and nursing care standard for patients with upper gastrointestinal tract bleeding?

\section{Subjects \& Methods \\ Research design}

Descriptive design was utilized to achieve the aim of the study. The primary objective of this research is to identify a problem to provide insights into and comprehension for more precise investigation it focuses on the discovery of ideas and thoughts.

\section{Setting}

The study was conducted in the department of the Tropical Medicine, Gastroenterology and Internal Medicine Department at EL Rajhi hospital, Assuit University.

Subjects

A sample of (60) nurse working with upper GIT bleeding patient in the Endoscopy Unit, Tropical Medicine Gastroenterology and Internal Medicine Department.

Study tools

Data pertinent to the study was collected utilized two tools.

Tool (I): Assessment of current nursing management for patient with upper gastrointestinal bleeding questionnaire .

This tool developed by the researcher based on literature review. Used to assess nursing management provided for patient with upper gastrointestinal bleeding it (Johnston et al., 2010). (Gralnek et al., 2015). \& (Wong et al., 2015).consists of three parts:Part 1: Demographic data; about the nurses such as: age, sex, marital status, educational qualification, years of experience, training course about upper GIT bleeding. It included 7 items (question from 1 of 7)

Part 2: Nurses' knowledge regarding upper gastrointestinal bleeding patients

This part to assess the nurses knowledge regarding to care of patient with upper GIT bleeding .This part included; definition of upper gastrointestinal bleeding, causes, symptoms , diagnosis, investigation, complication ,nursing management, routine nursing intervention, nursing intervention before, during and after end endoscopy, guidelines that given to patient before discharge. It included 14 items open end question and true \&false (22 Items) (question from 1 of 36)

Scoring system

The open ended questions was (14) questions. It used to measure the exact knowledge level of nurses about gastrointestinal bleeding. Each item was categorized and scored into complete correct $=(2)$, incomplete correct $=(1)$ and incorrect $=(0)$. The total score for all items was (28) score. In addition to true and false questions were (22) questions. Each item was categorized and scored into true $=(1)$, and false $=(0)$ the total score for all items was (22 degree)

According to range of total scores lie between (0-50) degrees Nurse's knowledge was classified as: Satisfactory knowledge $\geq 70 \%$ and unsatisfactory knowledge $\leq 70 \%$

Part 3: Nurses' practice observation checklist sheet to assess nurses' practice regarding upper gastrointestinal bleeding

This part included nurses practice related to procedure required for patient with upper gastrointestinal bleeding as assessing circulatory function (pulse, blood pressure, respiration, temperature) neurological function, administer of oxygen, peripheral venous catheter, intravenous infusion administration and discontinuing, blood transfusion, nasogastric tube insertion, administering an enema ,blood glucose monitoring and nurse's precaution for infection control.

Scoring system of nurses practice assessment tool Regarding observational checklist for the nurses this part that uses Likert scale. The total steps were (300) steps. It used to measure the exact practical level of nurses about caring of patient with gastrointestinal bleeding.

Scores assigned to each item are between 0 to 3 points as follows; (not done inapplicable $=(0)$, done in correct $=(1)$ and done correct $=(2)$. According to range of total scores lie between (0-600) degrees nurse's practice was classified as: Satisfactory (good) practice $\geq 70 \%$. and unsatisfactory (poor) practice $\leq$ $70 \%$

Developing nursing care standards for upper gastrointestinal bleeding

This standard was developed by the researcher after reviewing current national and international literature. And in order to elicit opinions of nurses as regard the basic nursing care stander for patient with upper GIT bleeding. This standard covered 7 major broad competencies which were further subdivided into sub competencies.

1. Ensures that the gastroenterology, and tropical medicine, and internal medicine department environment are ready to receive upper GIT bleeding patient (65 items)

2. Ensure that the gastroenterology tropical medicine and internal medicine department environment are safe to receive the upper GIT bleeding patients. (27 items) 
3. Ensure that continuous monitoring and recording are followed for upper GIT bleeding patients. (7 items)

4. Ensure that all infecting control measures are properly followed in all procedures. (15 items)

5. Ensure those health teams are properly attired for patient caring with upper GIT bleeding patient. (14 items)

6. Ensure that safety for each patient during transportation. (7 items)

7. Ensure that all staff (health team) follows ethics and patients right the gastroenterology tropical medicine and internal medicine department. (15 items)

The scoring system of the nurse's opinionnair was as follow

The total items for all the 7 major broad competencies were (150 items)

Score $(1$ degree $)=$ Agree and disagree $=(0$ degree $)$

Methods

\section{2- Operational design}

This study was carried out in three phases.

\section{Phase (1) Preparatory phase}

A review of current and past, local and international related literature in the various aspects of the problems using books, articles, periodicals and magazines were done. The proposed study setting was assessed for numbers of nurses in the tropical medicine and internal medicine department at EL Rajhy hospital, Assiut university.

\section{Content validity and reliability}

To achieve content validity of the tools, it was reviewed by three experts in the field of the study (medical and nursing) and necessary modifications were done. reviewed the tool for clarity, relevance, comprehensiveness, understanding, minor modifications that required correction was carried out accordingly .Reliability refers to the degree of consistency with which the instrument (The questionnaire) measures the thing it is supposed to be measuring. Reliability of tool was confirmed by Alpha cronbach test (0.95).

A pilot study: (exploratory phase)

A pilot study carried out in August (2018) to test the feasibility applicability, easiness for administrative and practicability of the study tools in $(10 \%)$ of sample (6 nurses) to evaluate the clarity and applicability of the study tools. Analyses of the pilot study revealed that minimal modifications are required. These modifications were done and the subjects were not excluded from the actual study because this minor modification not consider vital change in the meaning or content of the study tool.

\section{Administrative Design}

An official letter was issued from the Dean of the faculty of nursing to the head of the tropical medicine department at El-Rajhy hospitals soliciting the necessary approval to conduct the present research. Phase (3): Planning phase

Based on finding of the exploratory phase, the developing nursing care standard who was reviewed and the tools are checked for clarity, relevance was developed by the researcher, after extensive literature review considering the nursing ' needs and their levels of understanding.

\section{Phase (4): Implementation phase}

Data were collected from the Tropical, Medicine and Internal medicine in at EL Rajey hospitals from October (2018) to December (2018) by interviewing methods. Each nurse was informed with the purpose of the study. The investigator emphasized that the participation is voluntary and confidentially of data and anonymity of subjects will be assured through coding of all data. Verbal consent was obtained for each nurse was secured the study was carried out at three shifts.

- At initial interview the researcher introduce herself to initiate line of communication, explain the nature and purpose of the study and fill out the questionnaire sheet (tool I part 1,2) to assess nurse's knowledge about UGIT bleeding and assessment of nursing practice checklists (tool I part 3).

- Standards of nursing practice checklists were developed tool (II) to determine level of achievement of nursing care standards in this study.

\section{Ethical consideration}

- Research proposal was approved from ethical committee in the faculty of nursing.

- There is no risk for study subject during application of the research.

- Informed consent was obtained from nurses or guidance that is willing to participate in the study after explaining the nature and purpose of the study.

- Confidentiality of the collected data was assured.

- Nurses have the right to refuse to participate and or with draw from the study without any rational any time.

- Nurse's privacy and anonymity of the subject was considered during collection of data.

\section{Statistical design}

Collected data was analyzed and tabulated. The statistical Package for (SPSS) version (23) was used to analyze data. Descriptive statistics was used for the quantitative data in the all questionnaire and the demographic data.

Descriptive statistics included: frequencies, and percentages. Use Pearson chi-square (cross tabs test) 
between nurses knowledge and practice and Opinionnaire with socio demographic data were done, Pearson Correlation (Correlation is significant at the 0.05 level). The level of significance for this study was set at $(\mathrm{p} \leq 0.05)$ to detect any indication of differences found in the data available.

\section{Results and Analysis of Data}

Part 1: demographic characteristics of the study sample.

Table (1): Frequency disruption of demographic characteristics of the studied nurses $(\mathrm{n}=60)$.

\begin{tabular}{|c|c|c|}
\hline Characteristics & No & $\%$ \\
\hline $\begin{array}{l}\text { Sex } \\
\text { Male } \\
\text { Female }\end{array}$ & $\begin{array}{c}2 \\
58 \\
\end{array}$ & $\begin{array}{r}3.3 \\
96.7 \\
\end{array}$ \\
\hline $\begin{array}{l}\text { Age group } \\
20-<30 \text { years. } \\
30-<40 \text { years. } \\
<40 \text { years. }\end{array}$ & $\begin{array}{c}46 \\
10 \\
4 \\
\end{array}$ & $\begin{array}{c}76.7 \\
16.7 \\
6.6\end{array}$ \\
\hline Mean \pm SD & \multicolumn{2}{|c|}{$28.16 \pm 10.34$} \\
\hline $\begin{array}{l}\text { Marital Status } \\
\text { Single } \\
\text { Married } \\
\text { Divorced } \\
\end{array}$ & $\begin{array}{c}11 \\
47 \\
2 \\
\end{array}$ & $\begin{array}{c}18.3 \\
76.3 \\
3.3 \\
\end{array}$ \\
\hline $\begin{array}{l}\text { Qualifications } \\
\text { Diploma of nursing } 3 \text { years } \\
\text { Institute of nursing } \\
\text { Baccalaureate of nursing }\end{array}$ & $\begin{array}{c}16 \\
43 \\
1 \\
\end{array}$ & $\begin{array}{c}26.0 \\
71.7 \\
1.7 \\
\end{array}$ \\
\hline $\begin{array}{l}\text { Years of experience } \\
<5 \text { year. } \\
5-10 \text { year. } \\
>10 \text { year. }\end{array}$ & $\begin{array}{l}27 \\
16 \\
17\end{array}$ & $\begin{array}{l}45.0 \\
26.0 \\
28.3\end{array}$ \\
\hline $\begin{array}{l}\text { Previous training } \\
\text { Yes } \\
\text { No }\end{array}$ & $\begin{array}{l}18 \\
42\end{array}$ & $\begin{array}{l}30.0 \\
70.0\end{array}$ \\
\hline
\end{tabular}

Part (II): Nurses' knowledge regarding upper GIT bleeding.

Table (2): Percentage distribution for nurse's knowledge about upper GIT bleeding ( $N=60)$.

\begin{tabular}{|c|c|c|c|c|c|c|}
\hline \multirow[t]{2}{*}{ Variables } & \multicolumn{2}{|c|}{$\begin{array}{l}\text { Correct } \\
\text { complete }\end{array}$} & \multicolumn{2}{|c|}{$\begin{array}{c}\text { Correct } \\
\text { Incomplete } \\
\end{array}$} & \multicolumn{2}{|c|}{ Incorrect } \\
\hline & $\mathbf{N}$ & $\%$ & $\mathbf{N}$ & $\%$ & $\mathbf{N}$ & $\%$ \\
\hline 1. Definition of upper GIT bleeding & 40 & 66.7 & 18 & 30 & 2 & 3.3 \\
\hline 2. Causes of upper GIT bleeding & 31 & 51.7 & 27 & 45 & 2 & 3.3 \\
\hline 3. Treatment of upper GIT bleeding & 38 & 63.3 & 21 & 35 & 1 & 1.7 \\
\hline 4. How to avoid upper GIT bleeding & 19 & 31.7 & 34 & 56.7 & 7 & 11.7 \\
\hline 5. Signs and symptoms of GIT bleeding & 29 & 48.3 & 28 & 47.3 & 3 & 5 \\
\hline 6. Methods of diagnosis of UGIT bleeding & 35 & 58.3 & 14 & 23.3 & 11 & 18.3 \\
\hline 7. Investigation for UGIT bleeding & 31 & 96.9 & 1 & 3.1 & 0 & 0 \\
\hline 8. Nursing care during upper endoscopy & 15 & 25.6 & 35 & 58.3 & 9 & 15 \\
\hline 9. What is post endoscopy discomfort & 8 & 13.3 & 44 & 73.3 & 8 & 13.3 \\
\hline 10. How to avoid these discomfort & 13 & 21.7 & 38 & 36.3 & 9 & 15 \\
\hline 11. Post upper endoscopy nursing care & 13 & 21.7 & 39 & 65 & 8 & 13.3 \\
\hline 12. Post endoscopy complication & 11 & 18.3 & 21 & 35 & 28 & 48.7 \\
\hline $\begin{array}{l}\text { 13. Precaution to avoid complications after } \\
\text { upper endoscopy }\end{array}$ & 13 & 21.7 & 25 & 41.7 & 22 & 36.7 \\
\hline $\begin{array}{l}\text { 14. Health teaching given to the patient before } \\
\text { hospital discharge }\end{array}$ & 29 & 48.3 & 23 & 38.3 & 8 & 13.3 \\
\hline
\end{tabular}




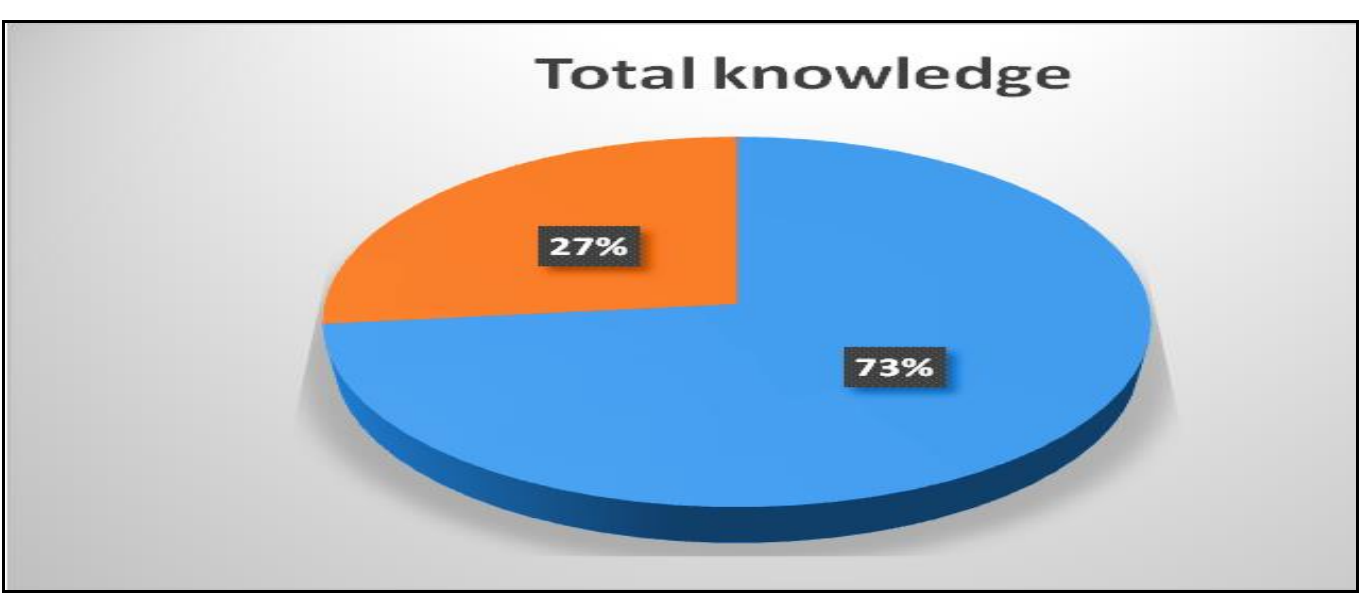

Figure (1): Distribution for level of nurse's knowledge regarding care of patient with upper GIT bleeding.

\section{TOTAL OPINNAIRE SHEET}

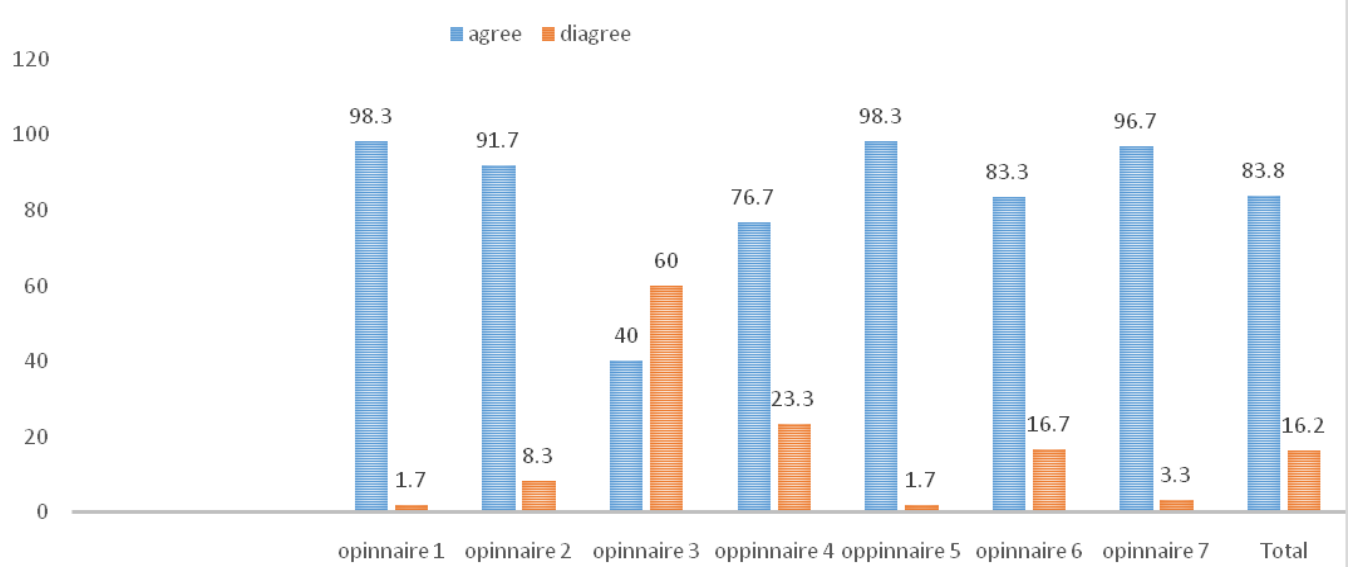

Figure (2): Frequent distribution of total opinnaire for nurse's regarding care of patient with upper GIT bleeding.

Table (3): Total nurses scores about nursing care standard for patient with upper gastrointestinal tract bleeding.

\begin{tabular}{|l|c|c|c|c|}
\hline \multicolumn{5}{|c|}{ Correlations } \\
\hline \multirow{2}{*}{} & & $\begin{array}{c}\text { Total } \\
\text { knowledge }\end{array}$ & $\begin{array}{c}\text { Total nursing } \\
\text { standard }\end{array}$ & $\begin{array}{c}\text { Total practice } \\
\text { score }\end{array}$ \\
\hline \multirow{2}{*}{ Total knowledge score } & Pearson Correlation & 1 & .253 & .131 \\
\cline { 2 - 5 } & Sig. (2-tailed) & - &. $\mathbf{0 5 1}$ & $.317^{\text {ns }}$ \\
\hline \multirow{2}{*}{ Total nursing standard } & Pearson Correlation & .253 & 1 & .267 \\
\cline { 2 - 5 } Total practice score & Sig. (2-tailed) & $\mathbf{. 0 5 1}$ & - &. $\mathbf{0 3 9}$ \\
\cline { 2 - 5 } & Pearson Correlation & .131 & .267 & 1 \\
\cline { 2 - 5 } & Sig. (2-tailed) & .317 & $\mathbf{. 0 3 9}$ & - \\
\hline
\end{tabular}

*. Correlation is significant at the 0.05 level (2-tailed). 


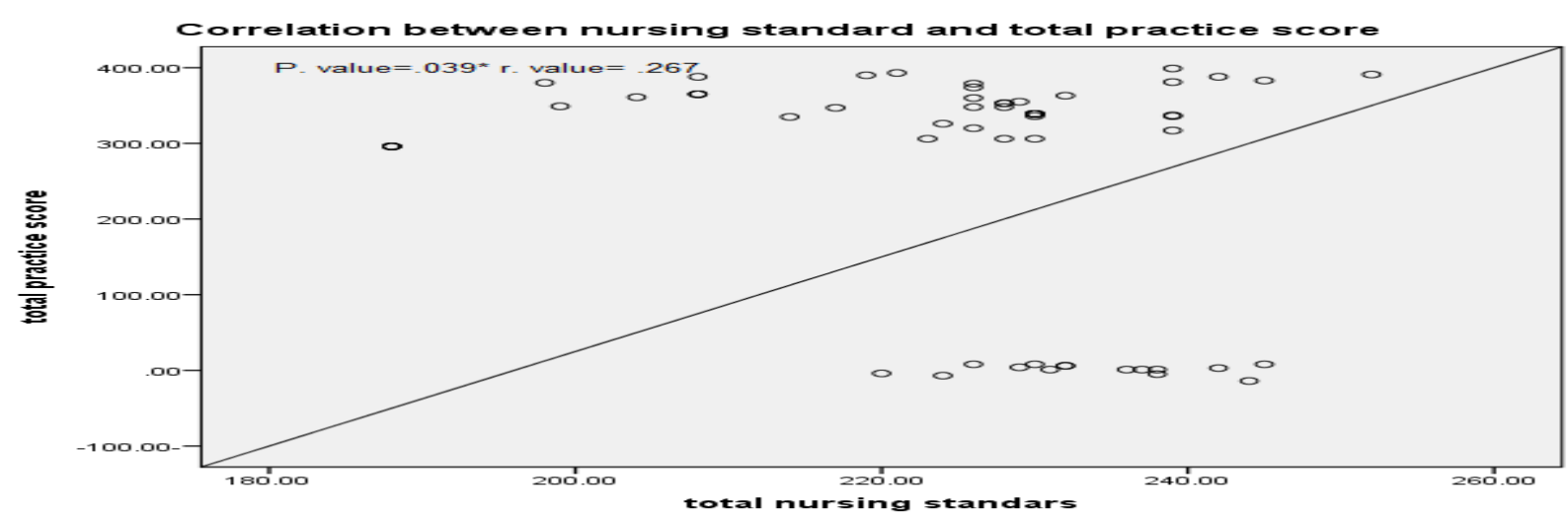

Figure (3): Correlation between nursing standard and total practice score regarding care of patient with upper GIT bleeding.

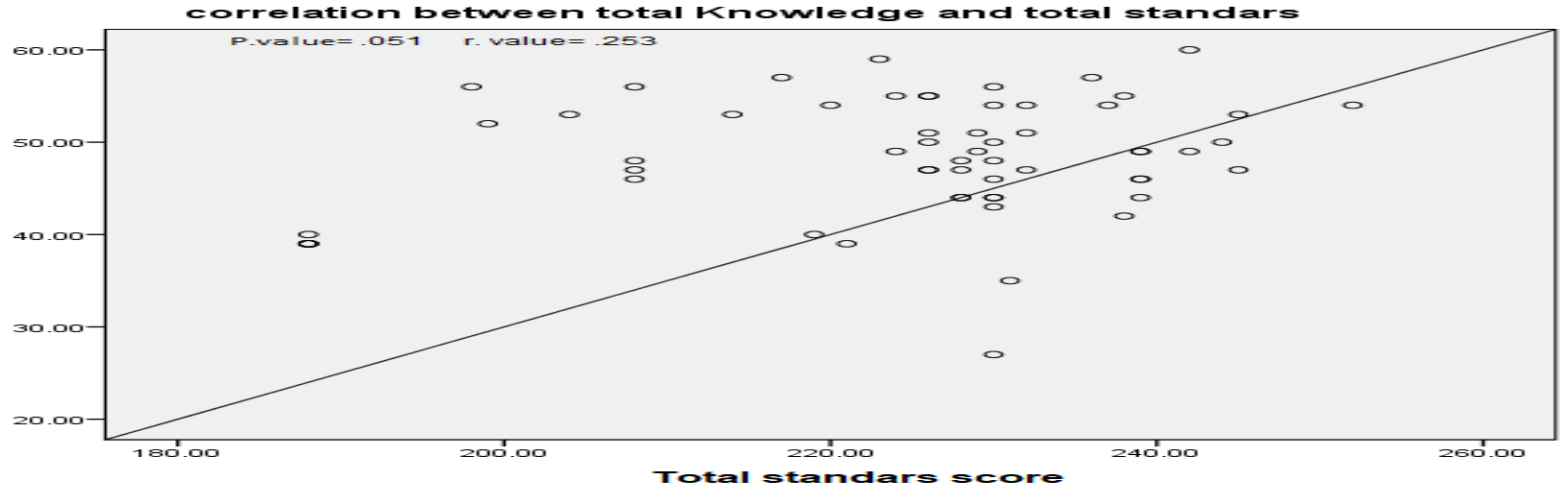

Figure (4): Correlation between nursing standard and total knowledge score regarding care of patient with upper GIT bleeding.

Table (1): this table show that the majority of nurses were female (96.7) their age group ranged from 20 30 years $(76.3 \%)$ and married (76.3).

And regarding qualifications; the majority of the study sample had institute of nursing. Also (45\%) of them had below 5 years of experience. And haven't received specialized training about upper GIT bleeding.

Table (2): This table represents that the majority of the study sample have the correct answer for definition of upper gastrointestinal tract bleeding, causes of upper GIT bleeding, Signs and symptoms, methods of diagnosis, investigation, treatment and health teaching given to the patient before hospital discharge in percentage of $(66.7,51.7,63.3,48.3$, $58.3,96.9,48.3 \%$ ) respectively.

Fig. (1): Represents that the majority of nurses have satisfactory level of knowledge $(73 \%)$ and $(27 \%)$ of nurses have unsatisfactory level as regarding care of upper gastrointestinal bleeding patient.
Figure (2): Show the level of total agreement as regarding to the nursing opinnaire in caring of patient with upper GIT bleeding.

Table (3) : there was a statistical difference between total nursing standard and total knowledge,practice score as regarding care of patient with upper GIT bleeding.

\section{Discussion}

Regarding demographic data of the studied nurse Discussion of the present study results were cover the following items: the demographic characteristics of the nurses, the knowledge and practice level regarding upper gastrointestinal bleeding, in addition to nursing care standards for upper gastrointestinal bleeding.

It revealed that the most of nurses' age ranged from 20 to 30 years and had nursing institution and around half of them had less than 5 years. This is in agreement with (Aby, 2015) who pointed in his study, that the most of the staff nurses were aged between 21-30 years. 
In addition, according to years of the experience categories the majority of the staff nurses less than five year of experience this agree with (Gijare, 2012) \& (El-Sheikh, \& Abed-Elsatar, 2013) who had the same finding and reported that the majority of the participant were less than 25 years of age and more than half of them were having from one-year to less than five years of experience.

Regarding nurses' knowledge about upper gastrointestinal bleeding

The present study revealed that there was satisfactory nurses' knowledge level regarding care of patient with upper GIT bleeding. This finding is in concordance with (Kojima, 2015) who indicated that there were highly significance differences through phases of study regarding knowledge and standard practice of universal precaution and endoscopic reprocessing for upper gastrointestinal bleeding patients care $(\mathrm{P}=0.0001)$ among studied nurses.

In addition, a study carried out by (Koshy, \& Patel, 2015) who pointed the knowledge scores of staff nurses regarding care of patient with upper gastrointestinal bleeding undergoing upper endoscopy was found to be highly significant $(\mathrm{p}<0.05)$. On the same line with this finding was (Maheswari \& Muthamilselvi, 2014) who pointed that over all knowledge mean and mean percentage were good. As well (Gijare, 2012) who reported that there was a highly significant difference in the overall knowledge \& practice among nurses.

Regarding the relation of the nurses' level of knowledge and their demographic characteristics there was no statistical significant deference except regarding previous training. This finding in agreement with the result of (Moqbel et al., 2015) who found that the knowledge score level of nurses who attaining training courses were higher score than those who did not attained any training courses. Also this study reveals more than half of nurses their age 21 to 30 years were having satisfactory level of knowledge, and nurses with institution education an less than 5 years of experience. This might be due to nurses who have more experience responsible for administrative activities and the younger newly graduated who recently attained training programs and fresh knowledge.

Regarding nurses' practice level about upper gastrointestinal bleeding nursing care

The present study indicates that the most of nurses had poor level in some items of practices. This might be related to the fact that nursing care standards about upper gastrointestinal tract bleeding practices consider new specialty. Also, there is no Arabic source for updating and continuing their education. The study finding is not agreement with (Moqbel et al., 2015) who demonstrated that minority of nurses had satisfactory level of practices in caring with upper gastrointestinal bleeding patient.

Regarding nursing care standard about upper gastrointestinal tract bleeding:

The nurse's practice regarding standard of care of upper GIT bleeding and GIT endoscopy care, the majority of them had agreed that ensures of the internal medicine department And Tropical Medicine department environment are ready to receive patient with GIT bleeding, as for prepare the department with necessary equipment, prepare patient room and components of internal medicine department. This finding may be related to that some nurses had long years of experience. Therefore, they aware of the necessary equipment and preparation for upper GIT bleeding in endoscopy patients.

Also the majority of them had agreed that; ensures that the internal medicine and Tropical medicine are safe to receive patient with GIT bleeding, this basic competency include hospital acquired infection, prevention from falling, reporting accidents and errors, maintaining safe environment of medication and maintaining comfort. The study result agree with (Aggarwal et al., 2010) who ensures that nurses working and caring for upper GIT bleeding and endoscopy in safe practice environment. Also safe environment or staff for increases the relation with high quality of care and patients outcomes also healthy productive work environment is wellestablished in the health care.

The present study reveal that around half disagreed with ensure that continuous monitoring and recording are followed for GIT bleeding patients, This not in the same line with (Feldheiser et al., 2016) who found that the majority of nurses agreed with continuous monitoring and recording are followed for GIT bleeding patients is very important to avoid complication and give discharge advise.

In relation to ensure that health team is properly attired for patient care, the majority of nurses agreed about this competency. This is in the same line with the study of (Sprecher et al., 2015) who stated that personal protective equipment is designed to protect the skin and the mucous membranes of eyes, nose and mouth of from exposure to blood or other potential infectious materials also protect patients. And this disagree with (Rosenthal et al., 2017) who revealed in his study that majority of studied nurses had a lack of adequate hand washing facilities, supplement of masks, gloves, caps, and gowns during maintenance care. Moreover, it may also be attributed to nursing staff shortage, nursing work overload, the time constrains of having to connect or disconnect a large number of patients within a limited time, and lack of awareness as a result of a lack of training programs. 
In relation to ensure that safety for each patient during transportation, all of nurses had agreed about this competency. Based on the present study, the majority of nurses had agreed about ensuring that safety for each patient during transportation from endoscopy unites to word. This result was in agreement with (Esmail et al., 2006) and (Shafa \& Lonstein, 2017). Who stated that staff orientation and training improved patient outcomes during transport. Especially the patient is always lifted from the bed, as opposed to being dragged or pulled with draw sheets, to prevent skin irritation or shearing. The nurse applies stretcher belts (restraints) prior to transport. Also, the head of the stretcher is elevated, side rails are raised, and the placement of tubes and drains is confirmed

Also agree with (Bailey et al., 2015) who mentioned that safety measures are implemented to prevent injury to both patient and staff members. The staff uses good body mechanics and assistive devices, such as draw sheets or body rollers, to allow proper weight distribution of the patient.

Most of the studied nurses agreed with ensures that all staff follow ethics and patient rights, this agreed with (Pettersson et al., 2018) who mention that the nurses in all contexts and domains of nursing practice and at all level of decision making should keep patients right and follow code of ethics it developed by nurses for nurses and can assist nurses in practicing ethically and working through ethical challenges that arise in their practice with individuals, families, communities and public health system.

In the present study there was no significant deference relationship between knowledge and practice Pearson Correlation Coefficient $(\mathrm{r}=0.131$ and $P$. value $=0.373$ ). This does not mean that knowledge does not play a role in practice. This could be most likely because of the attitude of nurses towards the practice of upper GIT bleeding and upper endoscopy patient care. This disagree with (Gijare, 2012) who reported in his study results regarding correlation between knowledge and practice, there was a correlation between auditing and re auditing knowledge and practice. But in this study also there was a statistical significant difference between nursing care standard and nurses performance in relation to care of patient with upper GIT bleeding this is agree with (El-Sheikh et al., 2011) who demonstrate in his study that the implementation of the standards care plane was very effective in enhancing nurses' practice regarding immediate post upper GIT bleeding

\section{Conclusion}

the majority of nursing has satisfactory level of knowledge but above third of nurse's perform the steps of observation checklist correctly and positive correlation between nursing standard and total practice \&knowledge score.

\section{Recommendation}

Application of nursing care standards for patient with upper GIT bleeding .Witten standard of nursing care for nurse to monitoring the routine nursing care daily.

\section{Reference}

1. Aby, A., (2015): A Study to Assess the Effectiveness of Structured Teaching Programme Regarding Knowledge on Nosocomial Infections, Vol. (5) No. (6), P.P. 245- 249

2. Aggarwal, R., Mytton, O., Derbrew, M., Hananel, D., Heydenburg, M., Issenberg, B., \& Ziv, A., (2010): Training and simulation for patient safety. British Medical Journal (BMJ), Quality and Safety, Vol. (19), No. (2), P.P. 34 43.

3. Bailey T., Keenan, R., Khanna, P., Kopicko, J., Fung, M., Bhakta, N., \& So, A., (2015): a randomized, double-blind, placebo-controlled study in patients with gout with inadequate response to standard of care. Vol. (76), No. (5), P.P.811:820

4. Diab, M., Shemis, M., Gamal, D., ElShenawy, A., El-Ghannam, M., El-Sherbini, E., \& Saber, M., (2018): Helicobacter pylori Western A genotype in Egyptian patients with upper gastrointestinal disease. Egyptian Journal of Medical Human Genetics, Vol. (19), No(4), P.P.297:300

5. El-Sheikh, A., \& Abed elsatar, O., (2013): The effect of implementing a control action plan for infection prevention at endoscopy unit. Egyptian Journal of Nursing, Vol.(1), No. (3), P.P. 64:84.

6. Esmail N., Escorsell, À., Pavel, O., Cárdenas, A., Morillas, R., Llop, E., Villanueva, C., \& Bosch, J., (2006): Esophageal balloon tamponade versus esophageal stent in controlling acute refractory variceal bleeding: A multicenter randomized, controlled trial. Hepatology, Vol.(63), No.(6), P.P.9571967

7. Feldheiser, A., Mashhour, A., Elbarmelgi, M., Raslan, M., Abdelsalam, A., \& Mohsen, A., (2016): pouch as neorectum after low rectal resection. The Annals of The Royal College of 
Surgeons of England, Vol. (99), No.(7), P.P.555:558

8. Gijare, M., (2012): Effectiveness of teaching on infection control practices among health care professionals. Journal of Nursing, Vol. (2), No. (2), P.P.5-9

9. Gralnek, I., Dumonceau, J., Kuipers, E., Lanas, A., Sanders, D., Kurien, M., \& Racz, I., (2015): Diagnosis and management of nonvariceal upper gastrointestinal hemorrhage: European Society of Gastrointestinal Endoscopy (ESGE) Guideline. Endoscopy, Vol.( 47), No.(10), P.P.1-46

10. Horve , S., Pan, C., \& Tepper, J., (2019): liver, Stomach, small and large intestines. Chapter (6) Adverse Late Effects of Cancer Treatment, Springer, Berlin, Heidelberg, p.p. 353-394.

11. Johnson M., Jefferies D., Langdon R., (2010): The Nursing and Midwifery Content Audit Tool (NMCAT): a short nursing documentation audit tool. Nursing management. Vol. (18), no. (7): P.P 832-845.

12. Kojima, G., (2015): Prevalence of frailty in nursing homes: a systematic review and metaanalysis. Journal of the American Medical Directors Association, Vol. (16), No. (11), P.P.940-945.

13. Koshy, S., \& Patel, R., (2015): Effectiveness of Planned Teaching Program on Knowledge Regarding the Infection Control Measures, International Journal of Innovative Research and Development, vol. (4), No. (4), P.P. 56- 70.

14. Maheswari, S., \& Muthamilselvi, G., (2014): Assess the Effectiveness of Structured Teaching Programme on Universal Precaution among Class IV Employees, International Journal of Healthcare Sciences. Vol.(3), No. (1). P.P.110:119.

15. Moqbel, A., Shebl, A., \& Soliman, H., (2015): Effectiveness of Planned Health Education Program on Nurses' Knowledge and Practice for Preventing Infection in Gastrointestinal Endoscopy Units at Major Hospitals in Yemen. Journal of Nursing and Health Science,(IOSR-JNHS), Vol (7), No. (56), P.P.1959:2320.

16. Pettersson J., Farrell, T., Bergman, S., Selim, N., Harzman, A., Schwarz, E., \& Scott, D., (2018): Evolution of practice gaps in gastrointestinal and endoscopic surgery, report from the Society of American Gastrointestinal and Endoscopic Surgeons (SAGES) Continuing Education Committee. Surgical endoscopy, Vol. (27), No. (12), P.P.4429-4438.
17. Rosenthal, Rocha, L., Pessoa, C., Neto, A., do Prado, R., Silva, E., de Almeida, M., \& Correa, T., (2017): Thromboelastometry versus standard coagulation tests versus restrictive protocol to guide blood transfusion prior to central venous catheterization in cirrhosis: study protocol for a randomized controlled trial. Vol. ( 18),No.(85), P.P. 1:10

18. Shafa A., Lonstein, M., (2017): The controversial experiments on the intravenous administration of drugs , Revista Médica de Chile, Vol. (143), No. (12), P.44

19. Sprecher, Sarazan, R., Mittelstadt, S., Guth, B., Koerner, J., Zhang, J., \& Pettit, S., (2015): Cardiovascular function in nonclinical drug safety assessment: Current issues and opportunities. International Journal of Toxicology, Vol.( 30),No.(3), P.P.272-286.

20. Wong, C., Odom, S. L., Hume, K., Cox, A., Fettig, A., Kucharczyk, S., \& Schultz, T., (2015): Evidence-based practices, A comprehensive review. Journal of autism and developmental disorders, Vol. (45), No.(7), P.P.1951-1966. 